\title{
A COMPARATIVE STUDY OF PRELOADING VERSUS COLOADING OF CRYSTALLOID TO PREVENT SPINAL ANAESTHESIA INDUCED HYPOTENSION
}

Siddharthkumar B. Parmar, Abdul Nasir A. Sheikh, Priyanka Sunil Shalu

1. Assistant Professor, Department of Anaesthesia, B. J. Medical College, Ahmedabad, Gujarat.

2. Assistant Professor, Department of Anaesthesia, B. J. Medical College, Ahmedabad, Gujarat.

3. Third Year Resident, Department of Anaesthesia, B. J. Medical College, Ahmedabad, Gujarat.

\section{CORRESPONDING AUTHOR}

Dr. Siddharthkumar B. Parmar, Tenament no. 516, Gayatri society, Sector- 27,

Gandhinagar, Gujarat. Pin 382028.

E-mail: drsid25@gmail.com,

Ph: 00919426332701.

ABSTRACT: CONTEXT: Preloading of crystalloid is a traditional practice to prevent spinal anaesthesia induced hypotension. But coloading seems to be more physiological and rational approach as effect was achieved during the time of spinal anaesthesia. AIMS: To compare crystalloid preload and coload for the prevention of spinal block induced hypotension in lower limb surgeries. Secondary outcomes included no. of dose of mephenteramine \& atropine, bradycardia, nausea, vomiting, total volume of infusion, blood loss \& urine output. SETTINGS AND DESIGN: Tertiary level, teaching hospital. Prospective, randomized study. MATERIALS AND METHODS: Total sixty patients of either sex, aged 20 to 60 years, scheduled for lower limb surgery under spinal anaesthesia were randomized into preload and coload group, 30 patients in each group. In preload group, $20 \mathrm{ml} / \mathrm{kg}$ of Ringer lactate was preloaded 20 minutes before commencement of spinal anaesthesia. In group Coload, $20 \mathrm{ml} / \mathrm{kg}$ of Ringer lactate was coloaded in 20 minutes just after lumbar puncture. STATISTICAL ANALYSIS USED: Quantitative data were compared with student's t test and qualitative data with chi-square or fisher exact test. $\mathrm{P}<0.05$ was considered significant. RESULTS: patient characteristics were comparable in both groups ( $p>0.05)$. Mean baseline value and trends at various time intervals of heart rate, systolic blood pressure, diastolic blood pressure, mean blood pressure were comparable in both groups. Total incidence of hypotension in group Preload and group Coload were $13.33 \%$ and 10\% respectively $(\mathrm{p}=0.463)$. Total incidence of bradycardia in group Preload and group Coload were $6.67 \%$ and $10 \%$ respectively ( $\mathrm{p}=0.394)$. No. of dose of atropine to treat bradycardia was 2 out of 30 patients $(6.67 \%)$ and 3 out of 30 patients $(10 \%)$ for group $P$ and $C$ respectively ( $p=0.394)$. No. of dose of mephenteramine to treat hypotension was 4 out of 30 patients $(13.33 \%)$ for each group (p=1). Incidence of nausea was $6.67 \%$ for group Preload and $10 \%$ for group Coload $(\mathrm{p}=0.394)$. Incidence of vomiting was $3.33 \%$ for group Preload and $6.67 \%$ for group Coload $(\mathrm{p}=0.278)$. Total volume used for preloading was about $1474 \pm 206 \mathrm{ml}$ and for coloading was $1386 \pm 176 \mathrm{ml}(\mathrm{p}=0.0805)$. Urine output in preloading and coloading groups was $223 \pm 100$ and $173 \pm 89 \mathrm{ml}$ respectively ( $\mathrm{p}=0.0453$ ). CONCLUSIONS: Coloading with $20 \mathrm{ml} / \mathrm{kg}$ of Ringer's lactate was as effective as preloading of same amount 20 minute before lumber puncture to prevent spinal induced hypotension.

KEY WORDS: preload, coload, ringer lactate, hypotension, spinal anaesthesia. 
INTRODUCTION: Spinal anaesthesia is a popular and well-accepted technique for surgery below umbilicus in adult patients ${ }^{1}$.

Hypotension following spinal anaesthesia (SA) is a common and troublesome complication ${ }^{2}$. Fluid administration before SA (preload) for the prevention of SA induced hypotension is a common and traditional practice in anaesthesia.

But, preloading of crystalloid is rapidly redistributed, and may induce atrial natriuretic peptide secretion, resulting in peripheral vasodilatation followed by an increased rate of excretion of the preloaded fluid. A more rational approach might be to apply fluid loading at the time that SA is starting to take effect. This might maximize intravascular volume expansion during vasodilatation from the sympathetic blockade and limit fluid redistribution and excretion ${ }^{3}$.

The present study was undertaken to compare the efficacy of crystalloid (Ringer lactate) preload versus coload for prevention of spinal induced hypotension in patients scheduled for lower limb surgeries under SA.

MATERIALS AND METHODS: The prospective, randomized study was conducted in tertiary level hospital and teaching institute. Approval of institutional ethical committee and informed written consent of patients was obtained. Total sixty patients of either sex, aged 18 to 60 years, American Society of Anaesthesiologist (ASA) physical status 1 or 2, with weight $<90 \mathrm{~kg}$ and height $>150 \mathrm{~cm}$ recruited for lower limb surgery under spinal anaesthesia. Exclusion criteria included obstetrical case, anatomically abnormal spine, hypertension, known cardiovascular disease, $\mathrm{Hb}$ less than $8 \mathrm{gm} / \mathrm{dl}$, bradycardia and any contraindications of SA. The patients were randomized using computer generated random numbers into group $\mathrm{P}$ (preload) and group $\mathrm{C}$ (coload) including 30 patients each.

All patients were fasted for 6 hours before surgery. On arrival to operation theatre, standard monitoring was instituted, including ECG, non-invasive blood pressure, pulse oximetry and baseline value were recorded. Baseline vitals of patient were recorded. 18 Gauge intravenous cannula was inserted in forearm.

In group P, $20 \mathrm{ml} / \mathrm{kg}$ Ringer lactate (RL) fluid was preloaded 20 minutes before commencement of surgery. In group C, $20 \mathrm{ml} / \mathrm{kg}$ RL fluid was coloaded in 20 minutes just after lumbar puncture (LP). Thereafter, all patients were infused $2 \mathrm{ml} / \mathrm{kg}$ of RL intraoperatively.

All patients received $3 \mathrm{ml}$ of $0.5 \%$ hyperbaric bupivacaine intrathecally, in L3-L4 intervertebral space with 23 Gauge spinal needle. After spinal injection, the patients were put in supine position. A sensory level T8 was achieved using pin prick to 25 Gauge needle. Urinary catheterisation was done. Heart rate (HR), systolic blood pressure (SBP), diastolic blood pressure (DBP), Mean blood pressure (MBP) and pulse oximetry (SPO2) were recorded every 5 minutes. Observations were recorded 50 minutes after administration of SA and the patients were handed over to the respective anaesthesia team for further management.

Hypotension was defined as fall in systolic blood pressure to less than $80 \%$ of the baseline value or systolic blood pressure less than $90 \mathrm{~mm}$ of Hg. One dose of Mephenteramine 3 $\mathrm{mg}$ was injected intravenously to treat each incidence of hypotension along with $200 \mathrm{ml}$ ringer lactate bolus. Bradycardia was defined as HR less than 55 beats per minutes and each incidence was treated with one dose of atropine $0.6 \mathrm{mg}$ intravenously. Incidence of hypotension, bradycardia, nausea and vomiting were noted. The number of doses atropine and mephenteramine drug was recorded. Total intravenous fluid, urine output (UO) and surgical blood loss were also noted.

Journal of Evolution of Medical and Dental Sciences/Volume1/Issue5/November-2012Page-747 
Data were analysed using Graphpad prism software version 5.1. We found that a sample size of 25 patients per group will be required (by a priori power analysis) to provide an $80 \%$ power of detecting an absolute difference of $25 \%$ in the incidence of spinal induced hypotension between the treatment groups, with and $\alpha=0.05$. accounting for possible dropouts, 60 patients were included in study. Student's t test was applied for quantitative data and Chi square for qualitative data. $\mathrm{P}$ value $<0.05$ was taken as significant.

RESULTS: Patients in both groups were well matched in terms of age, weight and sex. No statistical difference was seen in both groups.

The mean baseline of HR, SBP, DBP, MBP were comparable in both groups. The trends of HR, SBP, DBP, MBP at various time intervals were also comparable in both groups. Total volume used for preloading was about $1474 \pm 206 \mathrm{ml}$ and for coloading was $1386 \pm 176 \mathrm{ml}$ ( $\mathrm{p}=0.0805$ ). Urine output in preloading and coloading groups was $223 \pm 100$ and $173 \pm 89 \mathrm{ml}$ respectively $(\mathrm{p}=0.0453)$.

Total incidence of hypotension in group Preload and group Coload were $13.33 \%$ and $10 \%$ respectively $(\mathrm{p}=0.463)$. Total incidence of bradycardia in group Preload and group Coload were $6.67 \%$ and $10 \%$ respectively ( $\mathrm{p}=0.394)$. No. of dose of atropine to treat bradycardia was 2 out of 30 patients $(6.67 \%)$ and 3 out of 30 patients $(10 \%)$ for group P and C respectively $(\mathrm{p}=0.394)$. No. of dose of mephenteramine to treat hypotension was 4 out of 30 patients $(13.33 \%)$ for each group $(p=1)$. Incidence of nausea was $6.67 \%$ for group Preload and $10 \%$ for group Coload $(\mathrm{p}=0.394)$. Incidence of vomiting was $3.33 \%$ for group Preload and $6.67 \%$ for group Coload $(\mathrm{p}=0.278)$.

DISCUSSION: Ever since its introduction by august Bier4 in 1898, the popularity of SA has seen periods of waxing and waning in anaesthetist practice. With the introduction of safe local anaesthetic drugs and consequent reduction in the incidence of neurological complications, SA is still widely used in clinical practice.

Due to its advantage such as rapid onset of action, uniformly distributed analgesia, profound muscle relaxation, maintenance of clear mentation intraoperatively, blunting of stress response, good post-operative recovery, SA has replaced GA for lower abdominal and lower limb surgeries. SA has proved to be extremely safe when managed well; however, there is still a risk of complications. Some of the complications of SA are hypotension, bradycardia, total spinal anaesthesia and accidental intravascular injection. Hypotension is an important complication which may be preventable or avoidable.

Various techniques have been used to prevent SA induced hypotension. Some of these are preloading with IV fluids, low dose local anaesthetics in SA with or without additives and use of vasopressors prophylactically. Of these preloading with IV fluids has been considered safe and effective method. But, studies did not consistently prove the efficacy of preloading 5 and preloading before commencement of SA is time consuming. It is not possible to deliver preload in all the time with heavy routine work schedules and large no. of emergency surgeries in the second most populous country India. Attempts were done to use fluids after LP (coloading) instead of previous practice of preloading by various investigators with different success rate. In the present study, we have attempted to the study the efficacy of preloading versus coloading with RL in SA induced hypotension in lower limb surgeries.

In present study, we have used RL for preloading and coloading for SA as RL is the most commonly used fluid as a crystalloid in anaesthetic practice ${ }^{7}$. However, the best method of 
preloading, rate of administration, total volume of fluid remained controversial. Patients' characteristics were comparable in both groups. Mean baseline value and trends of HR, SBP, MBP, DBP were also comparable in both groups. Incidence of hypotension and bradycardia were comparable in both groups and thereby no. of dose of atropine and mephenteramine were also comparable in both groups. Incidence of nausea and vomiting were similar. Even though total IV fluids used were comparable in both groups but urine output were not comparable. Urine output was more in preload group which was suggestive of more redistribution and excretion associated with preloading. Nausea and vomiting were less in the preload group in our study, even though, the difference is not statistically significant.

Concept of coloading can be explained by the timing of hemodynamic events after SA. Sympathetic nerve blockade is completed within the first 10 minutes after administration of bupivacaine in subarachnoid space. There are high chance of hemodynamic changes like hypotension and bradycardia in this period. Preloading before commencement of SA may be effective but with considerable risk of volume overload. But, coloading makes available extra fluids in intravascular space during period of the highest risk of hemodynamic changes due to SA. So, it leads to timely compensatory changes in cardiovascular system and limits fluid redistribution and excretion with reduced risk of fluid overload. So, Coloading is physiologically more appropriate and rational approach.

Few studies are available in literature, which compares the effects of preloading and coloading in SA induced hypotension.

Kamenik $\mathrm{M}$ et al ${ }^{6}$ studied the effects of RL solution coload compared with preload, or no load on cardiac output after SA. They found that a sustained rise above baseline in coload group, whereas it returned to baseline in preload group and decreased in the group that received no fluid in general surgical population.

Ewaldsson CA et $\mathrm{al}^{7}$ found in their kinetic analysis of an IV infusion of RL as preload that a rapid fluid administration over two minutes after induction of spinal or general anaesthesia for non-obstetric surgery might prevent hypotension caused by central hypovolaemia.

Jose L. Mojica et al $^{\mathbf{8}}$ conducted a randomized clinical trial to evaluate the efficacy of crystalloids in preventing spinal-induced hypotension and cardiovascular side effects (CVSE) in total 404 surgical patients. Crystalloid administration at the time of spinal block resulted in an incidence of SIH almost identical to that seen in the Placebo group, but led to a significant reduction in the risk of CVSE as compared with placebo (RR, 0.23; $P=0.019$; number needed to treat,13) or with crystalloids administered before spinal block (RR, 0.26; $P=0.014$; number needed to treat, 14). Administering crystalloids at the time of spinal block had a beneficial effect in preventing CVSE in general and specialty surgery patients undergoing spinal anaesthesia as compared with administering crystalloids before spinal block or administering no crystalloids. This study favours the results of our study. But, we did not include any placebo or control group for ethical reasons in our study. So, the efficacy of crystalloid preloading in preventing SA induced hypotension could not be evaluated per se.

Our study confirms the finding of Manu Bose, et $\mathrm{al}^{9}$. They conducted a randomized study to compare the effect of preloading against coloading with $15 \mathrm{ml} / \mathrm{kg}$ ringer lactate in preventing hypotension and bradycardia following spinal anaesthesia in total 54 patients undergoing arthroscopies of lower limb. They found that trend of HR and MBP at various time intervals was comparable for both preloading and coloading groups. No. of incidence of bradycardia was $48.15 \%$ for both groups ( $\mathrm{p}$ value $=1$ ). No. of incidence of hypotension was $18.52 \%$ for 
preloading group and $11.11 \%$ for coloading group ( $p$ value $=0.140)$. Incidence of nausea and giddiness were comparable between two groups ( $\mathrm{p}=0.239$ and 0.491 respectively).

Jacob, et al ${ }^{10}$ Conducted a study of crystalloid preload versus coload for hypotension in 100 parturient scheduled for caesarean section under SA and found that incidence of hypotension was 30 in preload and 23 in coload group. High incidence of nausea (19 versus 10, $\mathrm{p}=0.0473$ ) and vomiting ( 14 versus $6, \mathrm{p}=0.0455$ ) in preloading group as compared to coloading group. The number of doses of ephedrine required $(\mathrm{p}=0)$ and the total dose of ephedrine used $(p=0.1528)$ in the groups were comparable. They concluded that both preloading and coloading with $15 \mathrm{ml} / \mathrm{kg}$ of RL were ineffective for SA induced hypotension. Frequent monitoring and prompt treatment with vasopressors were recommended. This study differs to our study by three ways: (1) They used $15 \mathrm{ml} / \mathrm{kg}$ RL solution (2) They included parturient (3) The patients were scheduled for caesarean section.

The drawbacks of our study are lack of a control group (no load) and non-blinding method. It is concluded that preloading before commencement of SA is not essential and coloading is equally effective for the prevention of SA induced hypotension. So, we believe that one should not spend valuable time to deliver preload before SA to prevent hypotension specifically in patients with ASA I \& II risk and unnecessarily delay surgery. Though care must be taken for parturient and patients with ASA >III risk.

CONCLUSION : Coloading with $20 \mathrm{ml} / \mathrm{kg}$ of ringer lactate is as effective as preloading with same volume over 20 minutes in the context of prevention of spinal induced hypotension in lower limb surgery. So, we believe that it is unnecessary to spend time to deliver preload and delay surgery for the prevention of SA induced hypotension.

\section{REFERENCES:}

1. Spinal anaesthesia - a practical guide http://update.anaesthesiologists.org/wp-content/uploads/2009/10/SpinalAnaesthesia-a-Practical-Guide.pdf

2. Bernd Hartmann, Axel Junger, Joachim Klasen, Matthias Benson, Andreas Jost, Anne Banzhaf, et al. The incidence and risk factors for hypotension after spinal anesthesia induction: an analysis with automated data collection. Anesth Analg 2002;94:1521-9.

3. RA Dyer, Z Farina, IA Joubert, P du Toit, M Meyer, G Torr, et al. Crystalloid preload versus rapid crystalloid administration after induction of spinal anaesthesia (coload) for elective caesarean section. Anaesth Intensive Care 2004; 32: 351-7.

4. K. Drasner. Spinal anaesthesia: a century of refinement, and failure is still an option. $\mathrm{Br} \mathrm{J}$ Anaesth 2009;102 (6):729-730.

5. Singh J, Ranjit S, Shrestha S, Sharma R, Marahatta SB. Effect of preloading on haemodynamic of the patient undergoing surgery under spinal anaesthesia. Kathmandu university medical journal 2010;8(2): 216-221.

6. Kamenik M, Paver-Erzen V. The effect of lactated Ringers solution infusion on cardiac output changes after spinal anesthesia. Anesth Analg 2001; 92: 710-14.

7. Ewaldsson CA, Hahn RG. Volume kinetics of Ringers solution during induction of spinal and general anaesthesia. Br J Anaesth 2001; 87:406-14. 
8. Mojica JL, Melendez HJ, Bautista LE. The timing of intravenous crystalloid administration and incidence of cardiovascular side effects during spinal anesthesia: the results from a randomized controlled trial. Anesth Analg 2002; 94: 432-37.

9. Manu Bose, Gurudas Kini, Krishna H.M. Crystalloid preload versus rapid crystalloid administration after induction of spinal anaesthesia (coload) for elective caesarean section J Anaaesth Clin P

10. Jevel J. Jacob, Aparna williams, Mary verghese, Lalita Afzal. Crystalloid preload versus crystalloid coload for parturients undergoing cesarean section under spinal anesthesia. Journal of Obstetric Anaesthesia and Critical Care 2012; 2(1): 10-15.

Table : 1 Patients's characteristics

\begin{tabular}{|l|l|l|l|}
\hline $\begin{array}{l}\text { Patient's } \\
\text { characteristics }\end{array}$ & $\begin{array}{l}\text { Group P } \\
(\text { Mean } \pm \text { SD) }\end{array}$ & $\begin{array}{l}\text { Group C } \\
(\text { Mean } \pm \text { SD) }\end{array}$ & $\begin{array}{l}\text { P value } \\
\text { (student"s t test) }\end{array}$ \\
\hline Age (years) & $32.63 \pm 10.73$ & $34.63 \pm 10.80$ & 0.4747 \\
\hline weight $(\mathrm{kg})$ & $54.4 \pm 8.20$ & $57.83 \pm 7.78$ & 0.1019 \\
\hline Sex (ratio) & $1: 1$ & $1: 1$ & - \\
\hline Total IV fluid $(\mathrm{ml})$ & $1205 \pm 187$ & $1214 \pm 163$ & 0.8432 \\
\hline Urine output $(\mathrm{ml})$ & $235 \pm 57$ & $203 \pm 46$ & 0.0166 \\
\hline
\end{tabular}

Table : 2 Perioperative adverse effects and use of drug.

\begin{tabular}{|c|c|c|c|c|c|}
\hline \multirow[t]{2}{*}{ Parameters } & \multicolumn{2}{|c|}{ Group P } & \multicolumn{2}{|c|}{ Group C } & \multirow[t]{2}{*}{ P Value } \\
\hline & No. & $\%$ & No. & $\%$ & \\
\hline Hypotension & 4 & 13.33 & 3 & 10 & 0.463 \\
\hline Bradycardia & 2 & 6.67 & 3 & 10 & 0.394 \\
\hline Atropin dose & 2 & 6.67 & 3 & 10 & 0.394 \\
\hline Mephenteramine dose & 4 & 13.33 & 4 & 13.33 & 1 \\
\hline Nausea & 2 & 6.67 & 3 & 10 & 0.394 \\
\hline Vomiting & 1 & 3.33 & 2 & 6.67 & 0.278 \\
\hline
\end{tabular}

Table : 3 Trends of HR and SBP among study groups.

\begin{tabular}{|l|r|l|r|r|r|r|r|r|}
\hline \multirow{4}{*}{ TIME } & \multicolumn{4}{|c|}{ HR } & \multicolumn{4}{c|}{ SBP } \\
\cline { 2 - 10 } & \multicolumn{2}{|c|}{ PRELOAD } & \multicolumn{2}{c|}{ COLOAD } & \multicolumn{2}{c|}{ PRELOAD } & \multicolumn{2}{c|}{ COLOAD } \\
\cline { 2 - 10 } & MEAN & SD & \multicolumn{1}{|c|}{ MEAN } & \multicolumn{1}{l|}{ SD } & MEAN & SD & MEAN & \multicolumn{1}{l|}{ SD } \\
\hline PREOP & 93.13 & 14.19 & 90.20 & 13.23 & 128.37 & 10.48 & 124.87 & 12.52 \\
\hline ON TABLE & 89.60 & 12.41 & 91.87 & 12.32 & 127.53 & 10.80 & 123.40 & 12.43 \\
\hline $\begin{array}{l}\text { PRELOAD 0 } \\
\text { MIN }\end{array}$ & 86.93 & 12.94 & 89.20 & 11.74 & 126.43 & 11.11 & 124.90 & 14.17 \\
\hline 5 MIN & 84.97 & 12.27 & 89.20 & 11.74 & 126.80 & 13.17 & 124.90 & 14.17 \\
\hline 10 MIN & 85.63 & 12.67 & 89.93 & 13.54 & 126.90 & 12.55 & 122.93 & 13.55 \\
\hline 15 MIN & 85.53 & 12.20 & 87.53 & 14.32 & 123.73 & 10.31 & 124.63 & 14.67 \\
\hline 20 MIN & 84.43 & 12.77 & 91.87 & 12.32 & 124.53 & 10.16 & 123.40 & 12.43 \\
\hline LP + COLOAD & 97.43 & 12.73 & 102.43 & 12.70 & 127.07 & 9.99 & 121.63 & 12.65 \\
\hline 5 MIN & 83.77 & 15.42 & 89.07 & 12.10 & 115.67 & 12.39 & 116.13 & 12.40 \\
\hline
\end{tabular}

Journal of Evolution of Medical and Dental Sciences/Volume1/Issue5/November-2012Page-751 
ORIGINAL ARTICLE

\begin{tabular}{|l|r|r|r|r|r|r|r|r|}
10 MIN & 85.63 & 12.67 & 89.93 & 13.54 & 114.53 & 10.84 & 118.60 & 9.40 \\
\hline 15 MIN & 82.83 & 13.75 & 88.17 & 13.41 & 117.57 & 10.12 & 116.03 & 10.62 \\
\hline 20 MIN & 83.93 & 12.04 & 82.83 & 13.75 & 118.13 & 9.28 & 117.57 & 10.12 \\
\hline 25 MIN & 82.20 & 12.05 & 83.93 & 12.04 & 118.43 & 7.62 & 118.13 & 9.28 \\
\hline 30 MIN & 80.57 & 11.57 & 82.20 & 12.05 & 117.97 & 8.65 & 118.43 & 7.62 \\
\hline 40 MIN & 80.83 & 9.99 & 80.57 & 11.57 & 118.63 & 8.19 & 117.97 & 8.65 \\
\hline 50 MIN & 81.37 & 9.58 & 81.93 & 11.86 & 116.67 & 9.17 & 115.63 & 10.52 \\
\hline
\end{tabular}
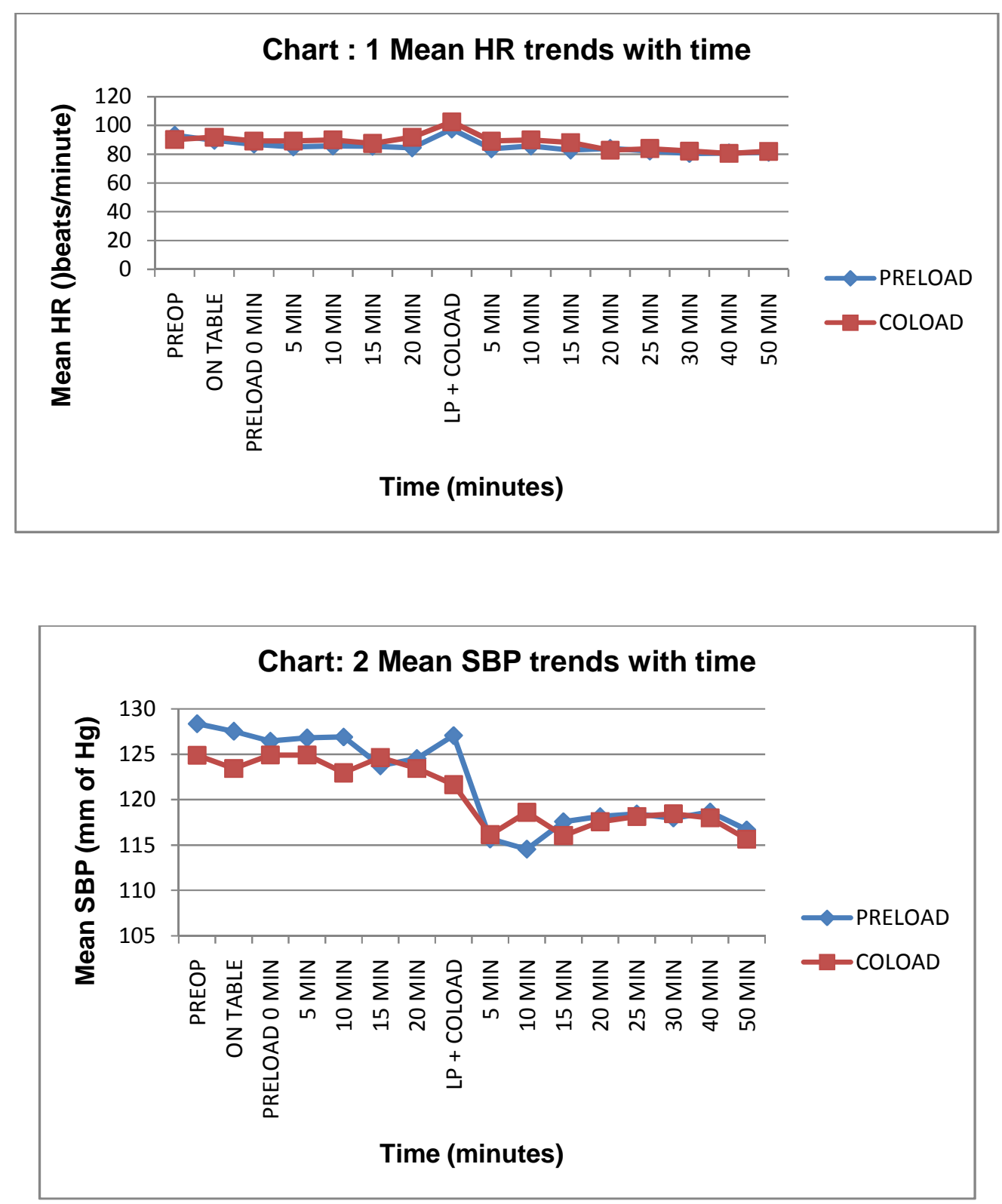

Journal of Evolution of Medical and Dental Sciences/Volume1/Issue5/November-2012Page-752 

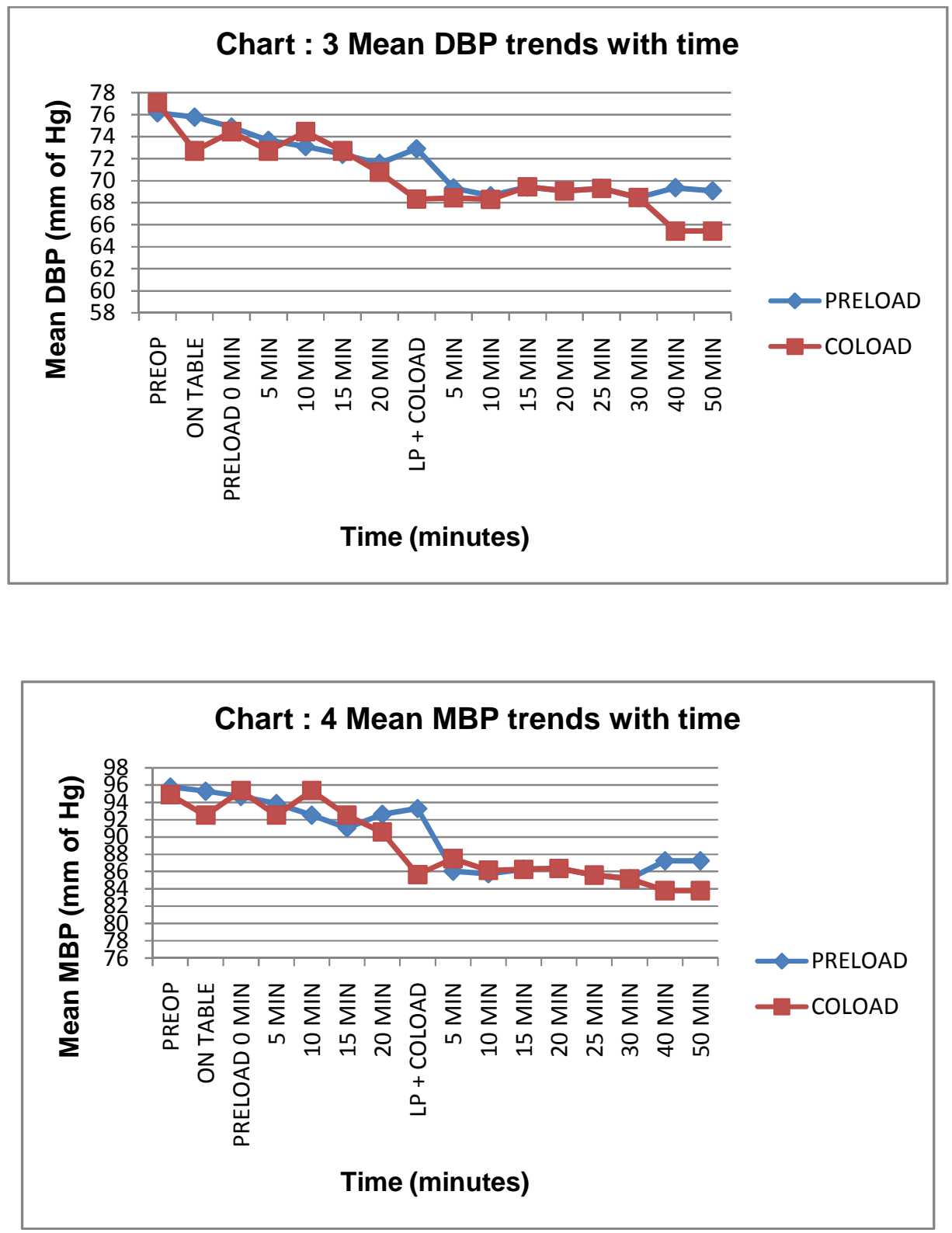